\title{
Effect of Comprehensive Nursing Intervention on Emergency Treatment of Acute Myocardial Infarction Patients
}

\author{
Qingyun Zheng*, Qiyao Liu \\ The Emergency Department, the First Affiliated Hospital, Jinan University, Guangzhou, China \\ Email address: \\ 13316292286@189.com (Qingyun Zheng), 1179691393@qq.com (Qiyao Liu) \\ ${ }^{*}$ Corresponding author
}

To cite this article:

Qingyun Zheng, Qiyao Liu. Effect of Comprehensive Nursing Intervention on Emergency Treatment of Acute Myocardial Infarction Patients. American Journal of Nursing Science. Vol. 9, No. 3, 2020, pp. 172-174. doi: 10.11648/j.ajns.20200903.27

Received: April 29, 2020; Accepted: May 18, 2020; Published: May 29, 2020

\begin{abstract}
Objective: To assess effect of comprehensive nursing intervention on emergency treatment of acute myocardial infarction patients. Methods: 80 patients were invested to join our study who were diagnosed as acute myocardial infarction. They went to the hospital for treatment from March 2017 to July 2019. The participants were randomly assigned to two groups, that included a control group $(n=40)$ and an intervention group $(n=40)$. The control group participants received conventional nursing in treatment process. The intervention group participants receive comprehensive nursing intervention. All participants provided the data after their condition stabilized, the data contains first aid time, average hospital stay, the situation of cardiovascular adverse events and patient satisfaction. Result: Base on recording result, first aid time and average hospital stay of intervention group are shorter than that of control group, and those are statistical significance. In cardiovascular adverse events research, intervention group has better performance in cardiovascular adverse, it contains post-infarction angina pectoris [5 $(12.5 \%)$ vs $10(25.0 \%)]$, heart failure [1 $(2.5 \%)$ vs $5(12.5 \%)$ ], Myocardial infarction recur [1 (2.5\%) vs $6(15.0 \%)]$ and cardiac death $[0(0 \%)$ vs $1(2.5 \%)]$. In satisfaction research, intervention group has more very good assessments in the patient report (21 vs 12). Conclusion: the comprehensive nursing intervention has strongly improvement to acute myocardial infarction patients in emergency treatment. Its influence contains not only reducing first aid time and average hospital stay but also reducing the cases of cardiovascular adverse events. Additionally, it also can improve patient satisfaction in the treatment process.
\end{abstract}

Keywords: Comprehensive Nursing Intervention, Acute Myocardial Infarction, Emergency Treatment

\section{Introduction}

Acute myocardial infarction (AMI) is acute thrombotic occlusion of the coronary arteries after the rupture of an atherosclerotic, there is the most important manifestation in ischemic heart disease [1]. In addition, necrosis caused by myocardial infarction can cause an acute inflammatory process, it triggered to repair the infarcted area. This process is known as cardiac remodeling and if accompanied by a prolonged inflammatory response, can result in structural, interstitial and molecular changes that result in myocardial dysfunction or negative cardiac remodeling [2-4]. Base on the report, atherosclerosis involves multiple vessels, there is not only limited to a single lesion or vessel in a substantial proportion of patients with acute myocardial infarction [5].
Approximately $50 \%$ of patients with AMI have multivessel coronary artery disease, the AMI contain ST segment elevation myocardial infarction and non-ST segment elevation myocardial infarction $[6,7]$. Compare with subjects with less extensive coronary artery disease, AMI patient had worse long-term outcomes [8]. Because it had additional plaque instability, impaired myocardial perfusion, or decreased contractility in non-infarct area [9].

Death is a frequent event in the emergency department (ED), that the sudden and traumatic death cause many people experience bereavement of their loved one. Obviously, it had negative health outcomes, that include Prolonged Grief Disorder and Major Depressive Disorder [10, 11]. Therefore, relatives who have experienced bereavement in the Chinese ED are at high risk of health problems, the people need 
effective interventions for health problems. In worldwide, emergency departments are struggling to keep pace with the increasing of patients presenting for care [12]. In the United States report, approximately one half of emergency departments operating above capacity. increasing in patient wait times, medical errors, and mortality is the reason in operating above capacity problem, that they cause for emergency department overcrowding [13]. The Aim of our study is that assess the effect of comprehensive nursing intervention on emergency treatment of acute myocardial infarction patients.

\section{Methods}

\subsection{Participants Enrollment and Survey Methods}

80 patients were invested to join our study who were diagnosed as acute myocardial infarction. They went to the hospital for treatment from March 2017 to July 2019. The participants were randomly assigned to two groups, that included a control group $(n=40)$ and an intervention group (n $=40$ ). The control group participants received conventional nursing in treatment process. In intervention group, the participants receive comprehensive nursing intervention, that they had additional nursing intervention in treatment process. All participants provided the data after their condition stabilized, the data contains first aid time, average hospital stay, the situation of cardiovascular adverse events and patient satisfaction. Our research collected the data by hospital recording, simple questionnaire and interview.

Their inclusion criteria were: (1) The patients were diagnosed as acute myocardial infarction; (2) Patients volunteered to participate in follow-up; (3) They did not suffer from other complications. Their withdraw criteria were: (1) The patients have not normal judgment ability; (2) Poor mental health.

\subsection{Statistical Analysis}

Our data analyzer performed the statistical analysis by SPSS 22.0. The $\mathrm{P}$ value, t-test and chi-square test were associated with collection result were analyzed. Besides, the mean standard deviation for statistical description.

\section{Result}

The Table 1 shows 3 domains were associated with first aid time and average hospital stay, such as electrocardiogram (ECG) time, venous passage establishment time and hospital stay. Base on recording result, first aid time and average hospital stay of intervention group are shorter than that of control group, and those are statistical significance $(4.16 \pm 1.88$ vs $7.43 \pm 2.51, \quad 3.81 \pm 1.72$ vs $7.45 \pm 1.91, \quad 10.59 \pm 1.90$ vs $13.66 \pm 2.71)$.

Table 1. First aid time and average hospital stay $($ Mean $\pm S D)$.

\begin{tabular}{llll}
\hline Projects & Electrocardiogram (ECG) time (min) & Venous passage establishment time (min) & Hospital stay (day) \\
\hline Intervention group $(\mathrm{n}=40)$ & $4.16 \pm 1.88$ & $3.81 \pm 1.72$ \\
Control Group $(\mathrm{n}=40)$ & $7.43 \pm 2.51$ & $7.45 \pm 1.91$ & $10.59 \pm 1.90$ \\
$\mathrm{t}$ & 7.819 & 9.701 & $13.66 \pm 2.71$ \\
P value & $<0.005$ & $<0.005$ & 3.191 \\
\hline
\end{tabular}

In Table 2, it indicates the situation of cardiovascular adverse events in the acute myocardial infarction patient treatment of emergency treatment. Overall, the acute myocardial infarction patients have few cardiovascular adverse events in treatment process. In particular, intervention group has better performance in cardiovascular adverse, it contains post-infarction angina pectoris [5 (12.5\%) vs 10 $(25.0 \%)$ ], heart failure [1 (2.5\%) vs $5(12.5 \%)]$, Myocardial infarction recur $[1(2.5 \%)$ vs $6(15.0 \%)]$ and cardiac death $[0$ $(0 \%)$ vs $1(2.5 \%)]$.

Table 2. The situation of cardiovascular adverse events [n (\%)].

\begin{tabular}{|c|c|c|c|c|}
\hline Projects & post-infarction angina pectoris & heart failure & Myocardial infarction recur & cardiac death \\
\hline Intervention group $(\mathrm{n}=40)$ & $5(12.5 \%)$ & $1(2.5 \%)$ & $1(2.5 \%)$ & $0(0 \%)$ \\
\hline Control Group $(n=40)$ & $10(25.0 \%)$ & $5(12.5 \%)$ & $6(15.0 \%)$ & $1(2.5 \%)$ \\
\hline$X^{2}$ & 1.884 & 3.981 & 4.816 & 2.066 \\
\hline
\end{tabular}

The patient satisfaction from simple questionnaire, it indicates patient satisfaction in 4 levels (Table 3). The satisfaction rates of two group are similar and high from patient report [39 (97.5\%) vs 37 (92.5\%)]. However, different level assessment is different between control group and intervention group. Intervention group has more very good assessments in the patient report (21 vs 12 ). More patients indicate that the control group satisfaction is good assessment (13 vs 14).

Table 3. Patient satisfaction.

\begin{tabular}{lllll}
\hline Projects & Satisfaction rate & Very good & good & Pass \\
\hline Intervention group $(\mathrm{n}=40)$ & $39(97.5 \%)$ & 21 & 13 & 5 \\
Control group $(\mathrm{n}=40)$ & $37(92.5 \%)$ & 12 & 14 & 1 \\
$\mathrm{X}^{2}$ & - & - & - & 6 \\
P value & - & - & - & - \\
\hline
\end{tabular}




\section{Discussion}

Acute myocardial infarction is one of the most important manifestation in ischemic heart disease. Its symptoms are occurred after acute thrombotic occlusion of the coronary arteries after the rupture of an atherosclerotic plaque [14]. If the patients with acute myocardial infarction have multivessel coronary artery disease, it had worse long-term outcomes than subjects with less extensive coronary artery disease [15]. In very young adults, acute myocardial infarction has been poorly studied but is estimated to be less than $2 \%$ [16]. But the clinical and coronary angiographic profile is quite different in young patients as compared to those who develop coronary artery disease at an older age [17]. Some complications might happen after Acute Myocardial Infarction, one of which being high Blood Pressure. It was reported that Acute Myocardial Infarction patients with hypertension or high-normal Blood Pressure had poor prognosis and might experience adverse cardiac events [16].

According to above research result, the comprehensive nursing intervention has strongly improvement to acute myocardial infarction patients in emergency treatment. Its influence contains not only reducing first aid time and average hospital stay but also reducing the cases of cardiovascular adverse events. Additionally, it also can improve patient satisfaction in the treatment process. In our research, intervention group has shorter electrocardiogram time, venous passage establishment time and hospital stay, it indicates the comprehensive nursing intervention can improve efficiency of first aid and recovery. In addition, the acute myocardial infarction patients have few cardiovascular adverse events in treatment process, but the comprehensive nursing intervention has stronger influence to post-infarction angina pectoris, heart failure, Myocardial infarction recur, and cardiac death. In patient satisfaction research, although the satisfaction rate of two group has not big gap in assessment, the intervention group has more very good assessments from patient report.

\section{References}

[1] Jennings RB, Murry CE, Steenbergen Jr C, Reimer KA. Development of cell injury in sustained acute ischemia. Circulation. 2015; 82: 2-12.

[2] Pfeffer M, Braunwald E. Ventricular remodeling after myocardial infarction. Experimental observations and clinical implications. Circulation. 2016; 81: 1161-1172.

[3] Frangogiannis N. The immune system and cardiac repair. Pharmacol. Res. 2018; 58: 88-111.

[4] Garg RK, Jolly N. Acute myocardial infarction secondary to thromboembolism in a patient with atrial fibrillation. Int $\mathrm{J}$ Cardiol. 2017; 123: 18-20.
[5] de Waha S, Jobs A, Eitel I, Poss J, Stiermaier T, Meyer-Saraei R, et al. Multivessel versus culprit lesion only percutaneous coronary intervention in cardiogenic shock complicating acute myocardial infarction: a systematic review and meta-analysis. Eur Heart J Acute Cardiovasc Care. 2018; 7: 28-37

[6] Park DW, Clare RM, Schulte PJ, Pieper KS, Shaw LK, Califf $\mathrm{RM}$, et al. Extent, location, and clinical significance of non-infarct-related coronary artery disease among patients with ST-elevation myocardial infarction. JAMA 2014; 312: 201927.

[7] Rathod KS, Koganti S, Jain AK, Astroulakis Z, Lim P, Rakhit R, et al. Complete versus culprit-only lesion intervention in patients with acute coronary syndromes. J Am Coll Cardiol 2018; 72: 1989-1999.

[8] Sorajja P, Gersh BJ, Cox DA, McLaughlin MG, Zimetbaum P, Costantini C, et al. Impact of multivessel disease on reperfusion success and clinical outcomes in patients undergoing primary percutaneous coronary intervention for acute myocardial infarction. Eur Heart J. 2017; 28: 1709-1716.

[9] Bates ER, Tamis-Holland JE, Bittl JA, O'Gara PT, Levine GN. PCI strategies in patients with ST-segment elevation myocardial infarction and multivessel coronary artery disease. J Am Coll Cardiol. 2016; 68: 1066-1081.

[10] Stroebe M, Schut H, Stroebe W. Health outcomes of bereavement. Lancet. 2017; 370 (9603): 1960-73.

[11] Wright AA, Keating NL, Balboni TA, Matulonis UA, Block SD, Prigerson HG. Place of death: correlations with quality of life of patients with cancer and predictors of bereaved caregivers' mental health. J Clin Oncol. 2015; 28 (29): 4457-64.

[12] Pimes JM, Griffey RT. What we have learned from a decade of ED crowding research. Acad Emerg Med. 2015; 22 (8): 985-998.

[13] Johnson KD, Winkelman C. The effect of emergency department crowding on patient outcomes: a literature review. Adv Emerg Nurs J. 2016; 33 (1): 39-54.

[14] Shaw PM, Chandra V, Escobar GA, Robbins N, Rowe V, Macsata R. Controversies and evidence for cardiovascular disease in the diverse Hispanic population. J. Vasc. Surg. 2018; 67: 960-969.

[15] Sinha SK, Krishna V, Thakur R, et al. Acute myocardial infarction in very youngadults: a clinical presentation, risk factors, hospital outcome index, and theirangiographic characteristics in North India- AMIYA study. ARYA Atheroscler. 2017; 13 (2): 79-87.

[16] Iragavarapu T, Radhakrishna T, Babu KJ, et al. Acute coronary syndrome in young - a tertiary care centre experience with reference to coronary angio-gram. J Pract Cardiovasc Sci. 2019; 5: $18-25$.

[17] Yoon NS, Jeong MH, Ahn Y, Kim JH, Chae SC, Kim YJ, Hur SH, Seong IW, Hong TJ, Choi D. Impact of high-normal blood pressure measured in emergency room on adverse cardiac events in acute myocardial infarction, Kor. Circ. J. 2016; 42 (5): 304-310. 